\title{
Linfoma NK/T extra nodal, tipo nasal, con compromiso cutáneo primario. Reporte de un caso
}

\author{
Extranodal Natural Killer/T-Cell Lymphoma, nasal-type with primary \\ cutaneous involvement. A case report
}

\author{
Marcos Silva-Feistner ${ }^{\mathrm{a}}$, María Jesús Rojas-Lechuga ${ }^{\mathrm{b}}$, Elena Ortiz ${ }^{\mathrm{a}}$, Montserrat Molgóa
}

aDepartamento de Dermatología, Facultad de Medicina, Pontificia Universidad Católica de Chile

bFacultad de Medicina, Pontificia Universidad Católica de Chile

Recibido el 17 de marzo de 2017; aceptado el 28 de diciembre de 2017

\begin{abstract}
Resumen
Introducción: El linfoma extranodal natural killer/célula T (NK/T) de tipo nasal, es una neoplasia poco frecuente, con una alta letalidad, caracterizada por destrucción ósea alrededor de los senos paranasales, el septum nasal u obstrucción de la vía aérea. Puede presentar compromiso primario de la piel, vía aérea y otros órganos. Objetivo: presentar un caso ilustrativo de una afección poco frecuente y de curso agresivo en población pediátrica, para facilitar la sospecha diagnóstica y el rápido reconocimiento por parte de los especialistas. Caso clínico: adolescente de 14 años, que consultó por lesiones solevantadas en brazos y piernas, no dolorosas, sugerentes de paniculitis subcutánea, las cuales evolucionaron a máculas violáceas ulceradas. La biopsia de las lesiones fue compatible con linfoma NK/T de tipo nasal. Fue derivada a oncología pediátrica, donde recibió tratamiento quimioterápico. Pese a los esfuerzos médicos, la paciente falleció a los 8 meses producto de una infección pulmonar grave secundaria a inmunosupresión. Conclusiones: El linfoma extranodal NK/T, tipo nasal es una neoplasia poco frecuente, que se comporta de forma agresiva, con una alta mortalidad sin tratamiento. Por lo que su reconocimiento es de gran relevancia para el diagnóstico precoz y rápida derivación a Hemato-Oncología.
\end{abstract}

\section{Abstract}

Introduction: Extranodal natural killer/T-cell lymphoma (NK/T), nasal type, is an infrequent neoplasm with a high lethality, characterized by bone destruction around the sinus, nasal septum or obstruction of the airway. Also, may be primary skin involvement, airway and other organs. Objective: Submit a rare condition in the pediatric population, in order to facilitate the diagnostic suspicion and quick recognition from specialists. Case report: a 14-year-old girl, who presented arm and leg lesions, painless, suggestive of subcutaneous panniculitis, which evolve to ulcerated purple maculae.
Palabras clave: Linfoma extranodal NK/T tipo nasal; Pediatría; Virus Epstein-Barr

Keywords:

Extranodal natural killer/T-cell lymphoma nasal type; pediatric; Ebstein-Barr virus 
Skin biopsy showed lesion compatible with NK/T lymphoma, nasal type. She was referred to pediatric oncology, where she received chemotherapy treatment. Despite medical efforts, the patient died eight months after due to a serious pulmonary infection secondary to immunosuppression. Conclusions: Extranodal NK/T-cell lymphoma, nasal type, is a rare neoplasm that behaves aggressively, with high mortality without treatment, therefore, its recognition has a high importance for early diagnosis and prompt referral to Hematology-Oncology.

\section{Introducción}

Los linfomas periféricos de células $\mathrm{T}$, son un grupo heterogéneo de neoplasias, que constituyen menos de un $15 \%$ de todos los Linfomas No Hodgkin (LNH) en adultos $^{(1,2)} \mathrm{y}$ menos de un $10 \%$ en población pediátrica y adolescente ${ }^{(1)}$. Entre ellos, se encuentra el Linfoma Extranodal NK/T tipo nasal o también llamado "linfoma angiocéntrico"(2).

Éste es un linfoma extranodal usualmente con fenotipo celular Natural Killer (NK) y positividad para virus Eipstein-Barr (VEB), presenta una amplia gama de manifestaciones y frecuentemente se presenta con necrosis y angioinvasión. Se denomina NK/T, debida a la ambigüedad de las células de origen, sin embargo, en su mayoría se debe a NK, y solo la minoría tiene células clonales $\mathrm{T}^{(3)}$.

El linfoma extranodal NK/T tiene una presentación clínica similar tanto en niños como en adultos, la enfermedad tiende a tener un predominio en hombres, la mayoría de los casos son diagnosticados en etapa precoz y frecuentemente se acompañan de síntomas $\mathrm{B}$ (baja de peso, sudoración nocturna y/o fiebre) y niveles de lactato deshidrogenasa (LDH) elevados. El más común de los linfomas extranodales es NK/T nasal, en el que el tumor puede causar destrucción ósea alrededor de los senos, el septum nasal u obstrucción de la vía aérea ${ }^{(4,5)}$, manifestándose con síntomas de obstrucción nasal, epistaxis y/o masa que comprometa la nariz, los senos o el paladar ${ }^{(1)}$. El linfoma extranodal NK/T de tipo nasal, se caracteriza por una ubicación primaria extra nasal ${ }^{(1)}$, el más frecuente de los compromisos extranasales es la piel, otros compromisos pueden ser vía aérea superior, el anillo linfático de waldeyer, tracto gastrointestinal, testículos, pulmón, ojos y partes blandas. Los linfonodos tienden a comprometerse de forma secundaria. El compromiso de médula ósea y síntomas B en estos casos, se observan en solo el 10$35 \%$ de los pacientes ${ }^{(6)}$.

La patogénesis es pobremente entendida, y es explicada en parte, por la infección por VEB de las células tumorales, junto con genes implicados en la angiogénesis, en la progresión del ciclo celular, genes supresores de tumores y entre otros ${ }^{(1,7)}$.

El linfoma extranodal NK/T es más frecuente en
Asia (China, Japón, Korea, Hong Kong), y en población nativa de América Central y Sudamérica, en los que se considera el 5-10\% de los LNH. La edad media de presentación es a los 45 años $^{(1)}$, sin embargo, se han reportado casos en la niñez ${ }^{(6)}$.

El objetivo es presentar un caso ilustrativo de una afección poco frecuente y de curso agresivo en población pediátrica, para facilitar la sospecha diagnóstica y el rápido reconocimiento por parte de los especialistas.

\section{Caso clínico}

Paciente de sexo femenino, de 14 años de edad, sin antecedentes mórbidos conocidos, acudió al Servicio de Dermatología por cuadro de 3 meses de evolución de lesiones asintomáticas en piernas. Al examen presentó una placa eritematosa de borde arciforme algo solevantado en relación a aspecto medial de la rodilla derecha (figura 1), a la dermatoscopía no se observó red pigmentaria, presentó múltiples vasos en coma, sin otras estructuras reconocibles. Se solicitó ecografía de partes blandas, que informó signos sugerentes de paniculitis subcutánea asociada a proceso inflamatorio dérmico, no se observaron imágenes sugerentes de necrosis grasa (figura 2).

Cinco meses posterior a la primera consulta, acudió la paciente a control, donde se observó máculas violáceas en sitios donde anteriormente se encontraban las lesiones. En este contexto, se decidió realizar biopsia cutánea, que informó piel con hiperqueratosis y exocitosis leve de linfocitos. Dermis con infiltrado linfocitario perivascular superficial, profundo y en hipodermis, denso, compuesto por linfocitos medianos a grandes, de núcleos irregulares, cromatina granular, con moderada cantidad de citoplasma claro. Se reconoció necrosis y numerosas mitosis atípicas (figura 3). El estudio inmunohistoquímico según técnica automatizada EnvisionFlex con anticuerpos monoclonales mostró reacción positiva para marcadores de células NK y reacción positiva para VEB según método FISH para los transcritos EBER1 y EBER2 (figura 4). Los hallazgos fueron compatibles con Linfoma-Leucemia NK/T de tipo Nasal. 


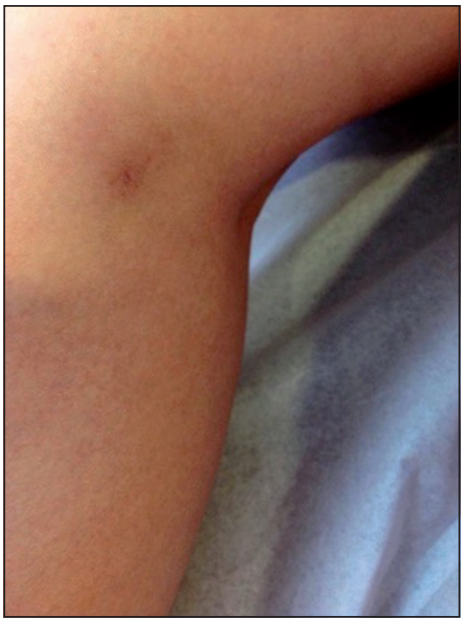

Figura 1. Placa eritematosa de borde arciforme levemente solevantado en relación a aspecto medial de la rodilla derecha.

En contexto del diagnóstico de un linfoma extranodal NK/T tipo nasal, con compromiso cutáneo primario, se solicitaron exámenes, en que destacó hemograma, pruebas hepáticas y perfil bioquímico normales, IgM VEB (-) e IgG VEB (+), Virus linfotrópico de células T humano Tipo I (HTLV1) (-). La paciente se derivó de forma urgente a HematoOncología, donde recibió dos ciclos de quimioterapia con ciclofosfamida, doxorrubicina, vincristina y prednisona $(\mathrm{CHOP})$, con respuesta parcial. Luego de 8 meses del diagnóstico la paciente falleció por progresión de su enfermedad asociada a complicación pulmonar infecciosa.

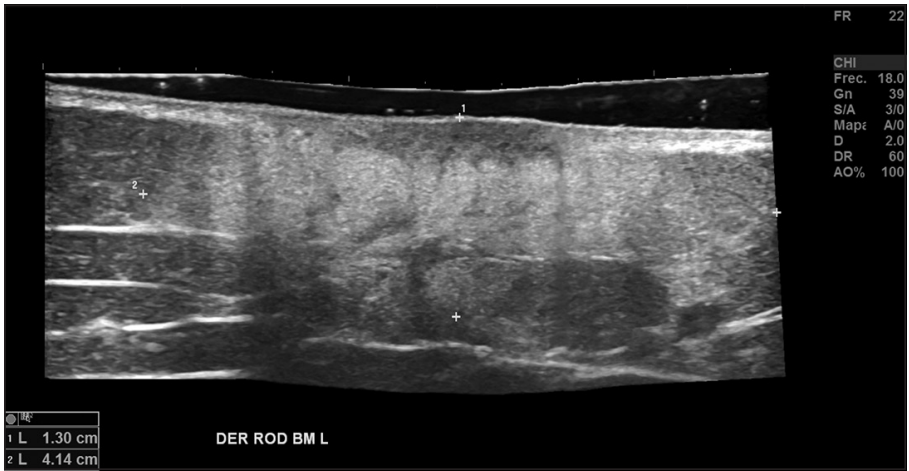

Figura 2. Ecografía de partes blandas de cara interna de rodilla derecha con signos sugerentes de paniculitis subcutánea asociada a proceso inflamatorio dérmico, no se observan imágenes sugerentes de necrosis grasa.

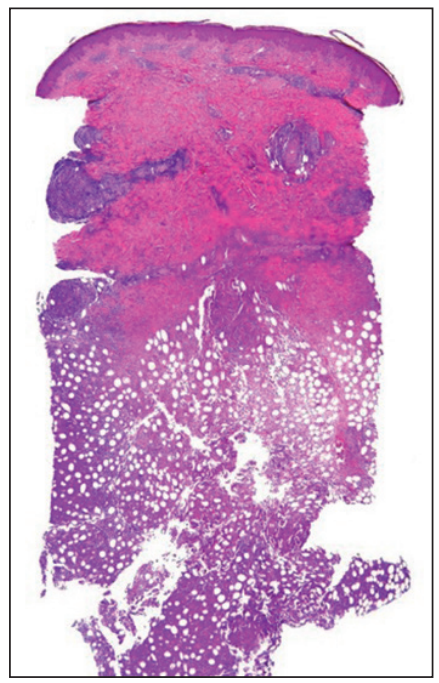

Figura 3. Corte histológico con tinción hematoxilina-eosina. Se observa dermis con infiltrado linfocitario perivascular superficial, profundo y en hipodermis, denso, compuesto por linfocitos medianos a grandes, de núcleos irregulares, cromatina granular, con moderada cantidad de citoplasma claro, necrosis y numerosas mitosis atípicas.

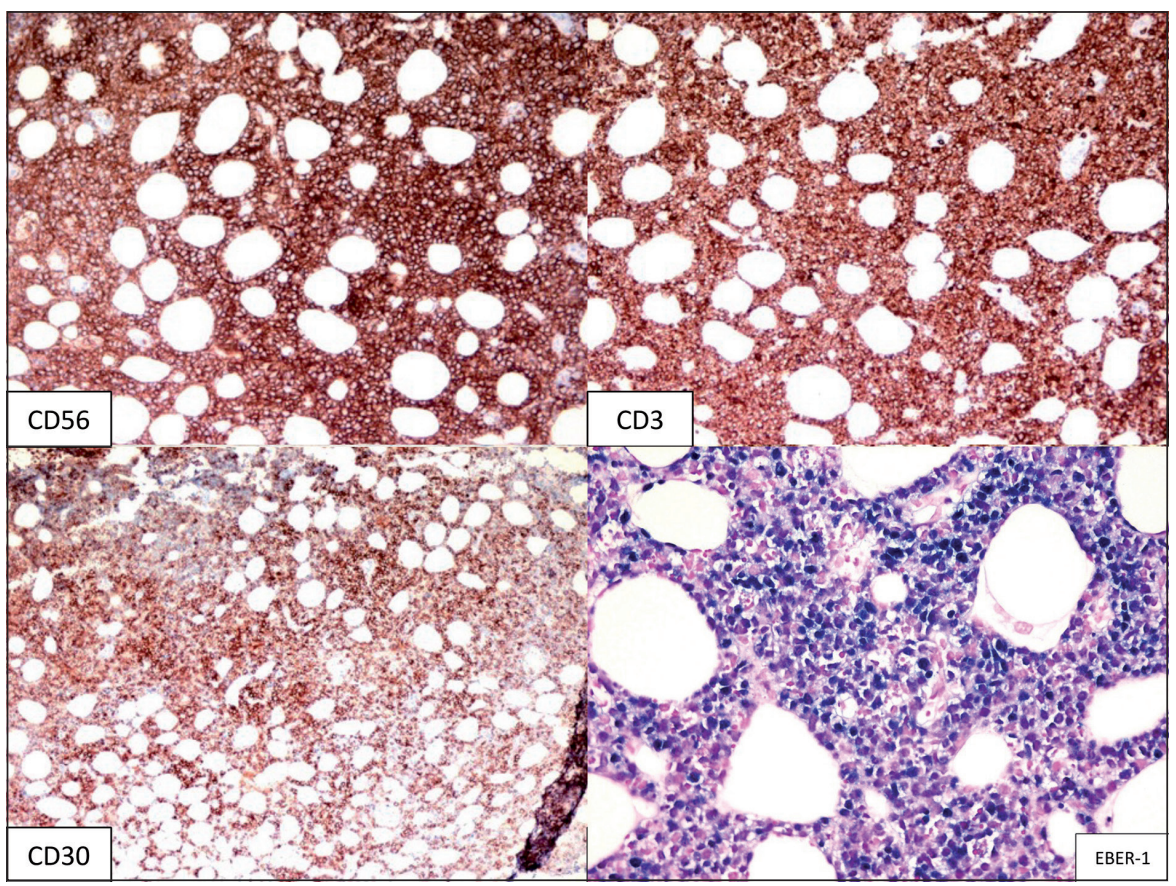

Figura 4. Estudio inmunohistoquímico según técnica automatizada EnvisionFlex con anticuerpos monoclonales, presenta reacción positiva para CD3, CD56 y CD30. Reacción positiva para transcrito EBER1 del Virus Epstein Barr según método FISH. 


\section{Discusión}

Pocos casos se han reportado de linfoma extranodal NK/T en niños y adolescentes, en los cuales, se ha observado que se encuentran precedidos por otros desórdenes relacionados al VEB como infección crónica activa por el virus, hipersensibilidad a picaduras de mosquitos $^{(8)}$, erupciones similares a Hydroa vacciniforme y linfohistiocitosis hemofagocítica ${ }^{(9)}$. Respecto a esta última, alrededor de un 3\% de éstos linfomas, puede asociarse con Síndrome Hemofagocítico, una complicación que puede presentarse con fiebre alta, rash maculopapular, falla de tratamiento, síntomas que comprometen el sistema nervioso central, hepatoesplenomegalia, linfadenopatías, citopenias, coagulopatías, alteración de pruebas hepáticas, y/o niveles altos de ferritina ${ }^{(10)}$. El linfoma extranodal NK/T no precedido por algunos de estos desórdenes mencionados, como es el caso de nuestra paciente, es extremadamente infrecuente en población pediátrica, y pocos casos han sido reportados ${ }^{(9)}$.

El diagnóstico se realiza con la evaluación clínica y biopsia del área comprometida, usualmente el área centrofacial. Por su morfología variable, es importante considerarlo como diagnóstico en todos los casos de linfoma extranodal agresivo asociado a invasión vascular y necrosis ${ }^{(11)}$.

Con respecto al compromiso cutáneo, alrededor de $2 / 3$ de los pacientes presentan celulitis y/o úlceras de predominio facial. Por lo que se debe tener un alto índice de sospecha por parte de dermatológos y pediatras, en caso de lesiones de éstas características que no $\operatorname{curan}^{(13)}$.

La histología que lo caracteriza, es un infiltrado polimorfo linfoide que invade las paredes vasculares, produciendo necrosis fibrinoide de la pared de los vasos y necrosis de los tejidos aledaños. Las células tumorales son variables en su morfología, en algunos casos puede tener predominio de células pequeñas o grandes, pero lo más frecuente es que sean mixtas. La clave diagnóstica está en la demostración de marcadores NK/T celulares y presencia de VEB. Si bien CD56 está típicamente expresado, hay tumores que no lo presentan y aun así se clasifican como linfoma extranodal NK/T, si tanto las moléculas citotóxicas como el VEB se encuentran positivos.

En el $90 \%$ de los casos en que éstos tumores son de origen en células NK, se expresan CD2, CD3 citoplasmático, CD56, y proteínas de gránulos citotóxicos; tienen genes receptores de células $\mathrm{T}$ en su configuración de línea germinal y son negativos para superficie $\mathrm{CD} 3^{(11)}$.

El linfoma extranodal de celulas NK/T tipo nasal es un linfoma agresivo, que sin tratamiento tiene una sobrevida de meses. El pronóstico con tratamiento está ampliamente relacionado con el compromiso y la etapa al momento del diagnóstico ${ }^{(12)}$. Respecto a la sobrevida, el compromiso cutáneo primario es el más frecuente en la forma extranasal, y se asocia a buen pronóstico. Por otra parte, el compromiso secundario cutáneo del linfoma extranodal nasal, se considera de peor pronóstico, por corresponder a una diseminación ${ }^{(13)}$.

En el caso de nuestra paciente, sospechamos que el desenlace desfavorable a pesar de presentar un compromiso cutáneo primario, puede encontrarse en contexto de que la ocurrencia y las características clínicopatológicas del linfoma NK/T extranodal en niños y adolescentes no precedido de otros desórdenes relacionados al VEB no han sido claramente establecidas ${ }^{(9)}$.

Estudios recientes han planteado como posibles factores de mal pronóstico los niveles de VEB, la invasividad del tumor y la expresión de antígenos ${ }^{(14)}$. Los valores séricos de anticuerpos para VEB (EA-IgA VEB $\geq 1: 10$ y VCA IgA $\geq 1: 160$ ) se han correlacionado recientemente con un peor pronóstico: menor sobrevida, menor supervivencia libre de progresión, una menor tasa de respuesta a tratamiento y mayor de recaídas. Estos niveles, por ende, pueden ser útiles a la hora de estratificación de riesgo y pronóstico en estos pacientes ${ }^{(15)}$. En el caso de nuestra paciente, no fueron realizados.

Debido a la agresividad de éste tipo de linfoma, es que frente al diagnóstico se debe realizar una derivación de forma urgente a Hemato-Oncología ${ }^{(16)}$. Respecto al manejo, se han planteado diversos esquemas, en el caso de linfoma NK/T nasal o paranasal se prefiere radioterapia con o sin quimioterapia. En enfermedad extranodal, se prefiere poliquimioterapia sistémica. El rol del trasplante de médula ósea es incierto en la literatura pediátrica, sin embargo, en la literatura oncológica, es una opción para pacientes con enfermedad no localizada en remisión ${ }^{(1)}$.

\section{Conclusión}

El linfoma extranodal NK/T de tipo nasal con compromiso cutáneo primario en una niña de 14 años, es una neoplasia extremadamente poco frecuente, más aún no precedido de otros desórdenes relacionados al VEB. Se caracteriza por presentar lesiones cutáneas inespecíficas. Se debe sospechar ante lesiones tipo celulitis y/o úlceras predominantemente en cara que no mejoran. Su diagnóstico es clínico e histológico, donde se caracteriza por presentar marcadores NK/T celulares, presencia de VEB y CD56.

Es una neoplasia maligna de alta agresividad, poco conocida, con malos resultados en sobrevida en niños y adolescentes, por lo que se requiere mayor profundización en la fisiopatología de la enfermedad y su manejo. 


\section{Responsabilidades Éticas}

Protección de personas y animales: Los autores declaran que los procedimientos seguidos se conformaron a las normas éticas del comité de experimentación humana responsable y de acuerdo con la Asociación Médica Mundial y la Declaración de Helsinki.

Confidencialidad de los datos: Los autores declaran que han seguido los protocolos de su centro de trabajo sobre la publicación de datos de pacientes.
Derecho a la privacidad y consentimiento informado: Los autores han obtenido el consentimiento informado de los pacientes y/o sujetos referidos en el artículo. Este documento obra en poder del autor de correspondencia.

\section{Conflicto de intereses}

Los autores declaran no tener conflicto de intereses.

\section{Referencias}

1. Termuhlen AM. Natural killer/Tcell lymphomas in pediatric and adolescent patients. Clin Adv Hematol Oncol. 2017;15(3):200-9.

2. Stein H, Warnke RA, Chan WC. Diffuse large B-cell lymphoma, not otherwise specified. In: Swerdlow SH, Campo E, Harris NL, et al, eds. WHO Classification of Tumors of Haematopoietic and Lymphoid Tissues. 4th ed. Lyon, France: IARC Press; 2008:233-9.

3. Harris NL, Jaffe ES, Stein H, Banks PM, Chan JK, Cleary ML, Gatter KC. A revised European-American classification of lymphoid neoplasms: a proposal from the International Lymphoma Study Group. Blood. 1994;84(5):1361.

4. Lee JY, Jang YD, Kim HK. The primary role of the otolaryngologist in managing pediatric sinonasal malignancies: an extranodal NK/T-cell lymphoma originating from the inferior turbinate mucosa of the nasal cavity. J Pediatr Hematol Oncol. 2008;30(5):401-4.

5. Lai C, Dunleavy K. NK/T-cell lymphomas in children. Best Pract Res Clin Haematol. 2013;26(1):33-41.
6. Au WY, Weisenburger DD, Intragumtornchai $\mathrm{T}$, et al. Clinical differences between nasal and extranasal natural killer/T-cell lymphoma: a study of 136 cases from the International Peripheral T-Cell Lymphoma Project. Blood. 2009;113(17):3931-7.

7. Asano N, Kato S, Nakamura S. EpsteinBarr virus-associated natural killer/Tcell lymphomas. Best Pract Res Clin Haematol. 2013;26(1):15-21.

8. Zhang Z, Shi Q, An X, et al. NK/T-cell lymphoma in a child with hypersensitivity to mosquito bites. J Pediatr Hematol Oncol. 2009;31(11):855-7.

9. Huang Y, Xie J, Ding Y, Zhou X. Extranodal Natural Killer/T-Cell Lymphoma in Children and Adolescents: A Report of 17 Cases in China. Am J Clin Pathol. 2016;145(1):46-54.

10. Brodkin DE, Hobohm DW, Nigam R. Nasal-type NK/T-cell lymphoma presenting as hemophagocytic syndrome in an 11-year-old Mexican boy. J Pediatr Hematol Oncol, 2008;30(12):938-40.

11. Kanavaros P, Lescs MC, Briere J, et al. Nasal T-cell lymphoma: a clinicopathologic entity associated with peculiar phenotype and with Epstein-Barr virus. Blood, 1993;81(10):2688-95.

12. Li CC, Tien HF, Tang JL, et al. Treatment outcome and pattern of failure in 77 patients with sinonasal natural killer/Tcell or T-cell lymphoma. Cancer. 2004;100(2):366-75

13. Choi YL, Park JH, Namkung JH, et al. Extranodal NK/T-cell lymphoma with cutaneous involvement: 'nasal' vs. 'nasal-type' subgroups--a retrospective study of 18 patients. Br J Dermatol. 2009;160(2):333-7.

14. Park S, Ko YH. Epstein-Barr virusassociated T/natural killer-cell lymphoproliferative disorders. J Dermatol. 2014;41(1):29-39.

15. Huang Y, Rao H, Yan S, et al. Serum EBV EA-IgA and VCA-IgA antibodies can be used for risk group stratification and prognostic prediction in extranodal NK/T cell lymphoma: 24 -year experience at a single institution. Ann Hematol. 2017;96(8):1331-42.

16. Wang ZY, Li YX, Wang WH, et al. Primary radiotherapy showed favorable outcome in treating extranodal nasal-type NK/T-cell lymphoma in children and adolescents. Blood. 2009;114(23):4771-6. 